\title{
Hyperkeratosis and Frictional Dermatitis from Practicing Kendo
}

\author{
Masuki Yoshida Naoki Oiso Akira Kawada \\ Department of Dermatology, Kinki University Faculty of Medicine, Osakasayama, \\ Japan
}

\section{Key Words}

Hyperkeratosis · Frictional dermatitis · Stamping · Friction $\cdot$ Kendo

\begin{abstract}
Repetitive mechanical activity induces a cutaneous reaction. A 22-year-old male presented with painful hyperkeratosis on the right heel. The hyperkeratosis had gradually developed after taking up the practice of Kendo. He also had slightly atrophic macules with scales on the left sole. We believe these lesions were caused by repeated stamping and friction during Kendo practice. Physical stresses can induce some types of skin disorders. We postulate that skin reactions caused by repetitive mechanical activity are more common than generally realized and that the interaction between physical activity and cutaneous reactivity must be examined more closely.
\end{abstract}

\section{Introduction}

Repetitive mechanical activity induces a cutaneous reaction. Here, we report a case of hyperkeratosis caused by repeated stamping and frictional dermatitis caused by repeated friction while practicing Kendo, a traditional Japanese martial art or sport.

\section{Case Report}

A 22-year-old male presented with painful hyperkeratosis on the right heel. The patient had practiced Kendo several days a week for 2.5 years. The hyperkeratosis had gradually developed after taking up the practice of Kendo. The patient had recently begun to feel pain. He also had asymptomatic, slightly atrophic macules with scales on the left sole and faint scales on the right toes (fig. 1). Kendo is played with bare feet on a wooden floor. This action causes repetitive mechanical damage to the soles of the feet (fig. 1). 


\section{Discussion}

The Kendo player wears protectors for the head, face, neck, forearms and trunk, and attacks an opponent with a kind of sword called 'shinai', made up of 4 bamboo slats held together by leather fittings. In the style called fumikomi-ashi, the player springs at the opponent from the left sole and strikes the wooden floor with the bare right heel. This style is used repeatedly in training and competitions.

We believe the lesions of our patient were caused by repeated stamping and friction during Kendo practice for 2.5 years (fig. 2). Physical stresses can induce some types of skin disorders. Repetitive frictional injury induces friction dermatitis and other forms of eczema, including juvenile plantar dermatosis, discoid eczema, hyperkeratotic palmar or plantar dermatitis and airbag dermatitis [1-3]. Repetitive mechanical activities involving friction, trauma, vibration and pressure can induce frictional hyperkeratotic hand dermatitis [4]. Mechanical factors such as trauma, friction, pressure, and vibration may induce frictional hand dermatitis [5] caused by repeated contact with carbonless copy paper, bus tickets [6], artificial fur [7], pantyhoses [8], and carpets [9].

McMullen and Gawkrodger [1] summarized 27 cases of dermatitis caused by frictional irritation and described the affected areas as the hands alone in 12 cases, fingers alone in 9 cases, hands and fingers in 2 cases, hands and feet in 2 cases, foot alone in 1 case, and the waist in 1 case. Saint-Martory pointed out that skin sensitivity was not restricted to the face but could be found in other areas, mainly the hands, but often the scalp and feet [10]. This suggests that palmoplantar sites are sensitive to physical irritation.

We postulate that skin reactions caused by repetitive mechanical activity are more common than generally realized. Therefore, the interaction between physical activity and cutaneous reactivity must be examined more closely. 


\begin{tabular}{c|l|l|l}
$\begin{array}{c}\text { Case Reports } h \\
\text { Demmitology }\end{array}$ & $\begin{array}{l}\text { Case Rep Dermatol 2010;2:65-68 } \\
\text { D0I: } 10.1159 / 000314318\end{array}$ & Published online: May 7, 2010 & $\begin{array}{l}\text { O 2010 S. Karger AG, Basel } \\
\text { ISSN 1662-6567 } \\
\text { www.karger.com/cde }\end{array}$ \\
\hline
\end{tabular}

Fig. 1. Clinical picture of hyperkeratosis on the right heel and slightly atrophic macules with scales on the left sole.

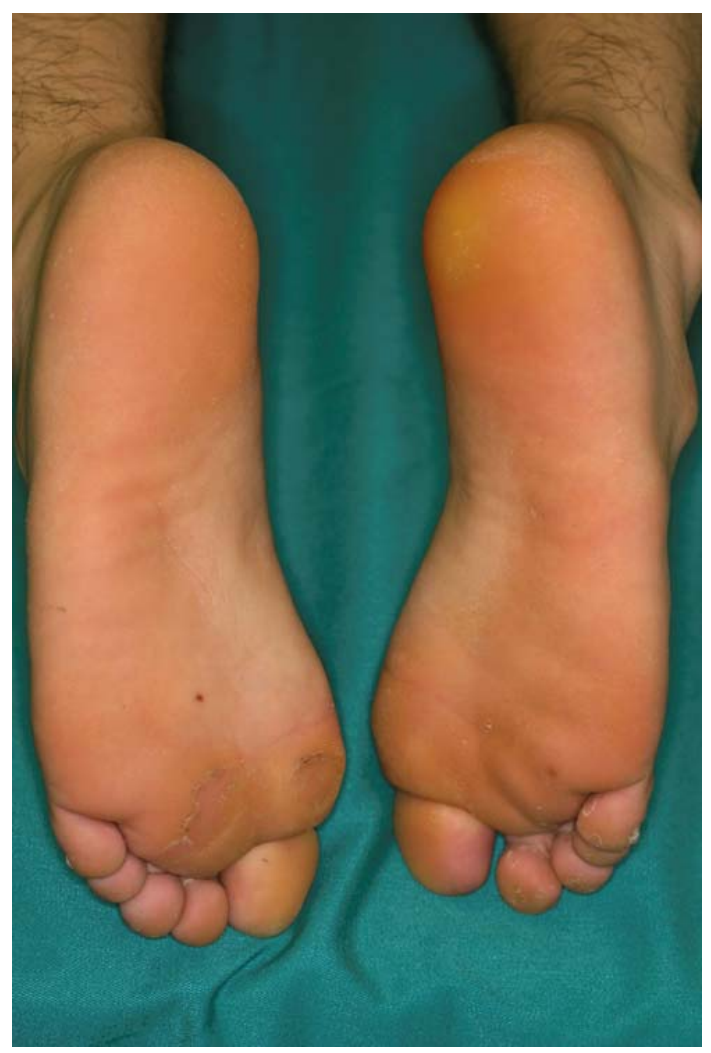

Fig. 2. The outline of the hypothesis. Repetitive mechanical activities of stamping may induce hyperkeratotic reaction.

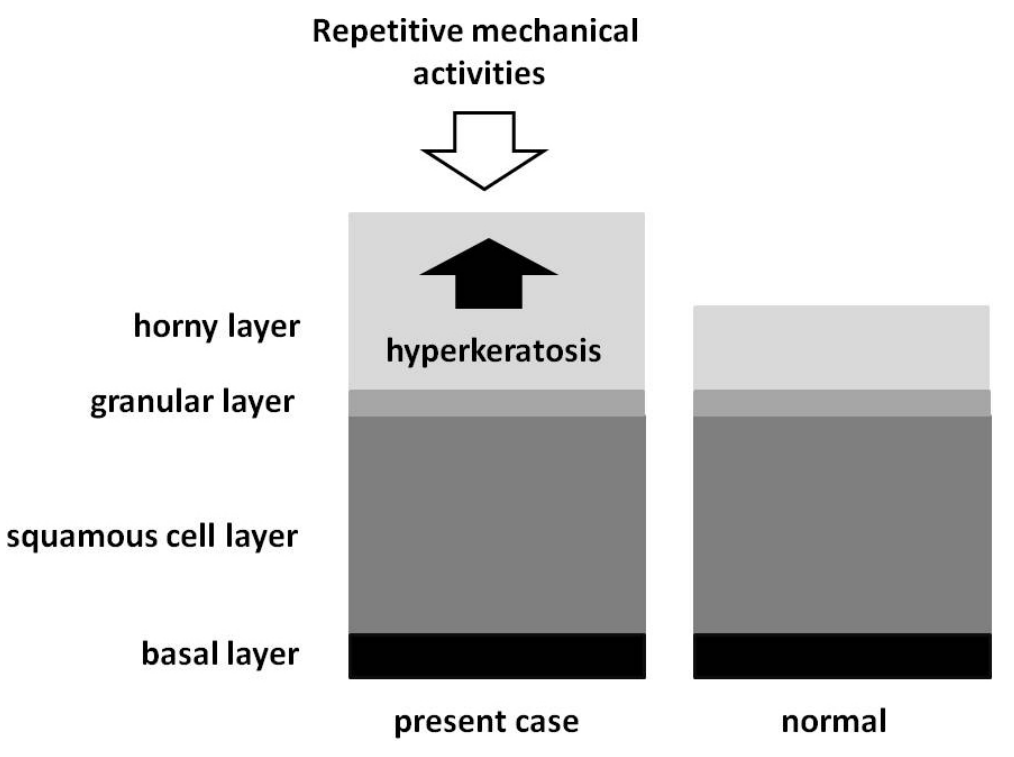




\section{References}

1 McMullen E, Gawkrodger DJ: Physical friction is under-recognized as an irritant that can cause or contribute to contact dermatitis. Br J Dermatol 2005;154:154156.

2 Inui S, Itami S: 2 cases of sumo wrestlers' friction dermatitis. Contact Dermatitis 2008; $58: 374-375$.

- 3 Inui S, Yamamoto S, Ikegami R, Ozawa K, Itami S, Yoshikawa K: Baseball pitcher's friction dermatitis. Contact Dermatitis 2002;47:176-177.

-4 Walling HW, Swick BL, Storrs FJ, Boddicker ME: Frictional hyperkeratotic hand dermatitis responding to Grenz ray therapy. Contact Dermatitis 2008;58:49-51.

5 Warshaw EM: Therapeutic options for chronic hand dermatitis. Dermatol Ther 2004;17:240-250.

-6 Menne T, Hjorth N: Frictional contact dermatitis. Am J Ind Med 1985;8:401-402.

7 Paulsen E, Andersen KE: Irritant contact dermatitis of a gardener's hands caused by handling of fur-covered plant ornaments. Am J Contact Dermat 1991;2:113116.

8 Gould WM: Friction dermatitis of the thumbs caused by pantyhose. Arch Dermatol 1991;127:1740.

9 Wahlberg JE: Occupational hyperkeratosis in carpet installers. Am J Ind Med 1985;8:351-353.

10 Saint-Martory C, Roguedas-Contios AM, Sibaud V, Degouy A, Schmitt AM, Misery L: Sensitive skin is not limited to the face. Br J Dermatol 2008;158:130133. 